Dicle University Journal of Engineering (DUJE)

Araștırma Makalesi / Research Article

\title{
Keyfi Şekilli Silindirlere Gömülü Dielektrik Cisimlerin Etkin Bir Mikrodalga Ters Saçılma Yaklaşımı ile Görüntülenmesi
}

\section{Imaging of Dielectric Objects Embedded in Arbitrary Shaped Cylinders through an Effective Microwave Inverse Scattering Approach}

\section{Tolga Ulaş Gürbüz*}

Gaziantep Üniversitesi, Bilgisayar Mühendisliği Bölümü, Gaziantep, tugurbuz@gantep.edu.tr, ORCID iD: 0000-0002-7834-0692

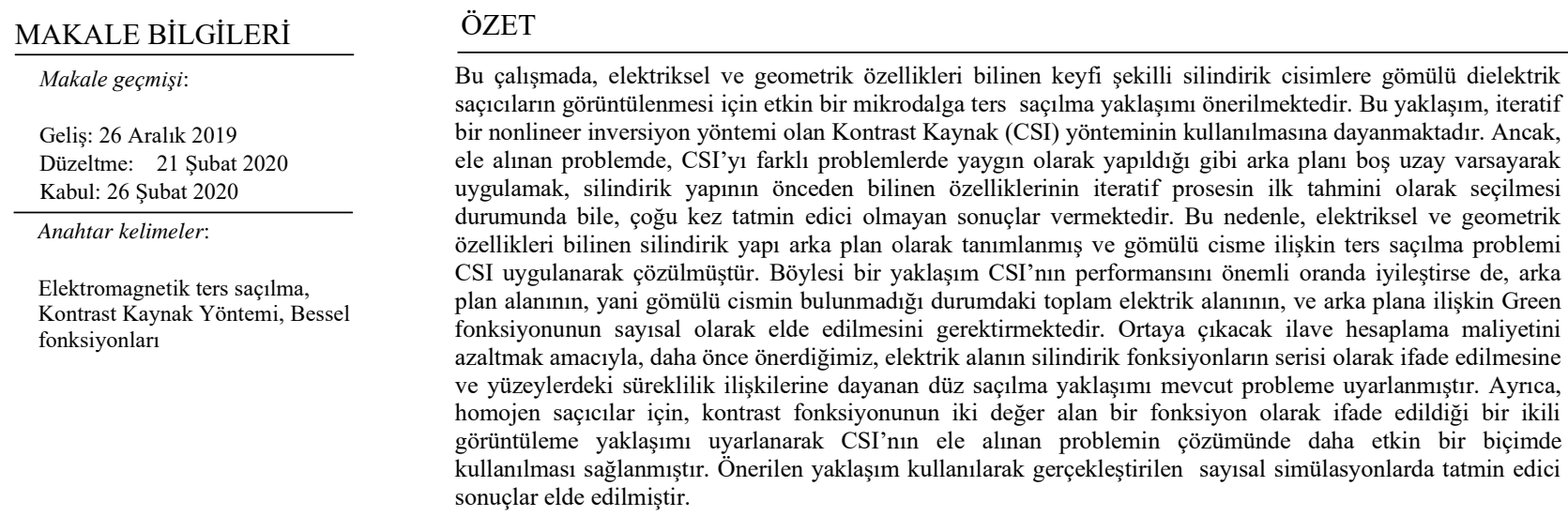

Doi: $10.24012 /$ dumf.665562

\begin{tabular}{|c|c|}
\hline ARTICLE INFO & ABSTRACT \\
\hline & \multirow{6}{*}{$\begin{array}{l}\text { In this study, an effective microwave inverse scattering approach for imaging of dielectric scatterers embedded } \\
\text { in arbitrary shaped cylindrical objects with known electrical and geometric properties is proposed. This approach } \\
\text { is based on the use of the Contrast Source Inversion (CSI), which is an iterative nonlinear inversion method. } \\
\text { However, applying CSI by considering that the background is free space, as is commonly done in various } \\
\text { problems, often yields unsatisfactory results for the problem at hand, even if priorly known properties of the } \\
\text { cylindrical structure are used as the first estimate of the iterative process. Therefore, the cylindrical structure } \\
\text { having known electrical and geometric properties is considered as the background and the inverse scattering } \\
\text { problem related to the embedded object is solved by applying CSI. Although such an approach considerably } \\
\text { improves the performance of CSI, it requires numerical computation of the background field, i.e. the total } \\
\text { electric field in the absence of the embedded object, and the Green's function of the background. In order to } \\
\text { reduce the additional computational cost, previously proposed forward scattering approach, which is based on } \\
\text { representation of the electric field as a series of cylindrical functions and the continuity relations on the } \\
\text { boundaries, is adapted to the problem at hand. Additionally, for homogeneous scatterers, an effective binary } \\
\text { imaging algorithm, in which the contrast function is expressed as a two-valued function, has been adapted. } \\
\text { Satisfactory results have been obtained in numerical simulations performed by using the proposed approach. }\end{array}$} \\
\hline Received: 25 December 2019 & \\
\hline Revised: 21 February 2020 & \\
\hline Accepted: 26 February 2020 & \\
\hline Keywords: & \\
\hline $\begin{array}{l}\text { Inverse electromagnetic } \\
\text { scattering, Contrast Source } \\
\text { Inversion, Bessel functions }\end{array}$ & \\
\hline
\end{tabular}

* Sorumlu yazar / Correspondence

Tolga Ulas GÜRBÜZ

$\triangle$ tugurbuz@gantep.edu.tr 


\section{Giriş}

Şekli ve elektriksel özellikleri bilinen bir cismin içerisine gömülü saçıcıların görüntülenmesi problemi, biyomedikal görüntüleme, tahribatsız muayene, jeofizik gibi farklı alanlarda sıkça karşılaşılaşılabilen bir problemdir. Literatürde bu problemin çözümü amacıyla mikrodalgaların kullanıldığ 1 pek çok çalışma mevcut olup [1-5], bu çalışmaların bir kısmında mikrodalga tomografisi yaklaşımı benimsenmiştir. $\mathrm{Bu}$ yaklaşım, görüntülenmek istenen bölgenin belirli sayıda mikrodalga kaynağı ile ayrı ayrı aydınlatılması ve her aydınlatma için, saçılan alanın belirli sayıda alıcı aracılığıyla ölçülmesine dayanır. Toplanan bu veri farklı inversiyon yöntemlerinde kullanılarak, görüntülenmek istenen bölgedeki malzemelerin geometrik ve/veya elektriksel özellikleri elde edilmeye çalış1lır [6].

Mikrodalga tomografisi kullanılarak yapılan çalışmaların bir kısmında gömülü saçıcıları barındıran cisimler keyfi şekillidir [3-5]. Biz bu çalışmada, bu tür problemler için tatmin edici doğrulukta sonuçların makul bir hesaplama süresi içerisinde elde edilmesini sağlayacak bir yaklaşım öneriyoruz. Bu yaklaşımla, iteratif bir doğrusal olmayan inversiyon yöntemi olan Kontrast Kaynak (CSI) [7,8] yönteminin, keyfi şekilli cisimlere gömülü saçıcıların görüntülenmesi probleminin çözümünde etkin biçimde kullanılabilmesi sağlanmaktadır. Genel anlamda CSI, görüntüleme problemini, bilinen bir uzayda bulunan bir cismin elektriksel parametrelerinin, veri ve cisim denklemi adı verilen iki integral denklem aracılığıyla belirlenmesi şeklinde ele alır. Kötü kurulmuş [9] ve doğrusal olmayan bu problemin çözümü için, sadece veri hatasını değil cismin üzerinde indüklenen akıma ilişkin hatayı da içeren bir hata fonksiyonu iteratif olarak minimize edilir. CSI kullanılarak, problemin doğasındaki nonlineerlik ihmal edilmeden ve her iterasyon adımında düz problemin çözümüne ihtiyaç duyulmadan, tatmin edici sonuçlar elde etmek mümkündür. Ancak, bu çalışmanın konusunu oluşturan problemde, CSI'y1 farklı problemlerde yaygın olarak yapıldığı gibi arka planı boş uzay varsayarak uygulamak, silindirik yapının önceden bilinen özelliklerinin iteratif prosesin ilk tahmini olarak kullanılması durumunda bile, çoğu kez tatmin edici olmayan sonuçlar vermektedir. Farklı çalışmalar, şekli ve elektriksel özellikleri bilinen yapıyı arka plan olarak tanımlamanın ve problemi buna göre formüle ederek, gömülü cismin elektriksel özelliklerinin bu arka planın elektriksel özelliklerine göre kontrastını görüntülemeye çalışmanın çok daha etkili bir yaklaşım olduğunu ortaya koymuştur [3]. Ancak böylesi bir yaklaşım, arka plan alanının, yani gömülü cismin bulunmadığı durumdaki toplam elektrik alanının, ve arka plana ilişkin Green fonksiyonunun sayısal olarak elde edilmesini gerektirmektedir. $\mathrm{Bu}$ aşamada ortaya çıkacak ilave hesaplama süresini azaltmak için ise, daha önce [10]'da verdiğimiz, elektrik alanın silindirik fonksiyonların serisi olarak ifade edilmesine ve yüzeylerdeki süreklilik ilişkilerine dayanan düz saçılma çözümünün mevcut probleme uyarlanmasinı öneriyoruz. Bunlara ek olarak, gömülü saçıcının, elektriksel özellikleri bilinen homojen bir cisim olduğu özel durumda, [11]'de farklı bir gradyan tabanlı inversiyon yönteminde kullanılmış olan ve kontrast fonksiyonun iki değer alan bir fonksiyon olarak ifade edilmesine dayanan ikili görüntüleme yaklaşımı uyarlanarak CSI'nın ele alınan problemin çözümünde daha etkin bir biçimde kullanılması sağlanabilir.

Yukarıda özetlediğimiz yaklaşımın ayrıntıları ve simülasyonlarda elde edilen sonuçlar aşağıdaki bölümlerde verilmektedir. $\mathrm{Bu}$ çalışmanın tamamında zamana bağlı değişimin $e^{-i \omega t}$ şeklinde olduğu varsayılmıştır ve sadelik amaciyla, bu ifade denklemlerde gösterilmemiştir.

\section{Problemin Formülasyonu}

Şekil 1'de, $z$ ekseni boyunca şekli ve malzeme özellikleri değişmeyen ve $x y$ düzlemi üzerinde D bölgesini kaplayan silindirik bir cisim görülmektedir. Cismin içerisinde, malzeme özellikleri ve $x y$ düzlemi üzerinde kapladığı $\mathrm{G}$ bölgesi bilinmeyen bir başka saçıcı bulunmaktadır. Büyük cismin dielektrik geçirgenliği ve elektrik iletkenliği sırası ile $\varepsilon_{1}$ ve $\sigma_{1}$ iken gömülü saçıcı için bu parametreler, $\boldsymbol{r}=$ $(\rho, \phi)$ kutupsal koordinatlarda konum vektörü olmak üzere, $\varepsilon_{G}(\boldsymbol{r})$ ve $\sigma_{G}(\boldsymbol{r})$ 'dir. Bütün malzemeler nonmagnetiktir, yani magnetik geçirgenlik katsayıları boşluğun magnetik geçirgenlik katsayısı olan $\mu_{0}$ 'a eşittir. Büyük cismin yüzeyi $\Gamma$ ile gösterilmiş olup, bu yüzeyin 
bilindiği ve $f$ tek-değerli bir fonksiyon olmak üzere, kutupsal koordinatlarda $\rho=f(\phi), \phi \in$ $[0,2 \pi)$, şeklinde ifade edilebildiği varsayılmaktadır. Gömülü cismin elektriksel ve geometrik özelliklerini belirlemek amacıyla, büyük cismi içine alan bir eğri üzerine dağıtılmış mikrodalga kaynaklar kullanılır; bu kaynaklar Şekil 1'de kırmızı renkli çarpı işaretleri ile temsil edilmektedir. Bu kaynaklarla yapılan her aydınlatma için, gelen elektromagnetik dalganın cisimler ile etkileşiminin ürünü olan elektrik alan vektörü cismin etrafındaki $\mathrm{S}$ bölgesine dağılmış noktalarda ölçülür.

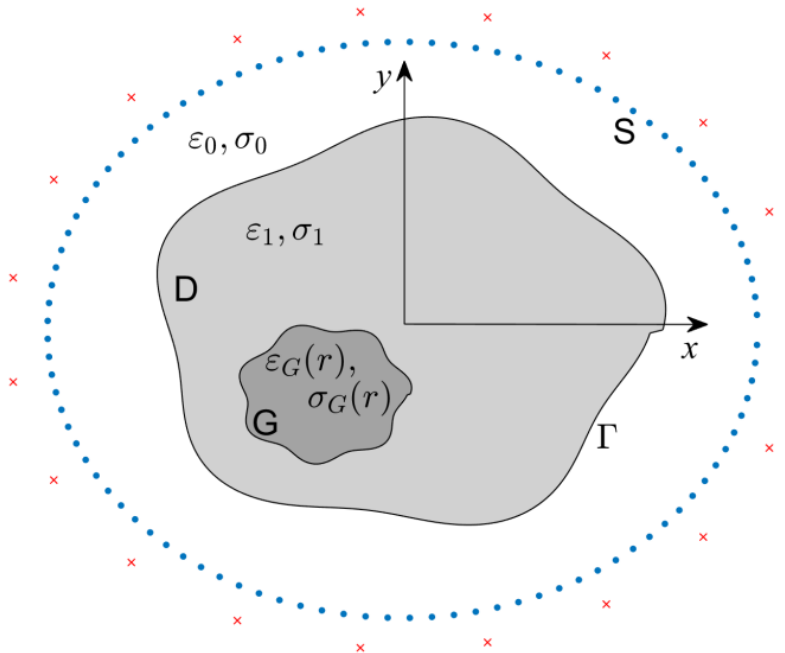

\section{Şekil 1. Problemin geometrisi}

$\mathrm{Bu}$ çalışmada, kaynakların zamanda harmonik alanlar ürettiği ve herhangi bir j'inci kaynak için gelen elektrik alan vektörünün, $\boldsymbol{e}_{\boldsymbol{z}}$ vektörü $z$ yönündeki birim vector olmak üzere, $\boldsymbol{E}_{j}^{i}(\boldsymbol{r})=$ $u_{j}^{i}(\boldsymbol{r}) \boldsymbol{e}_{\boldsymbol{z}} \quad$ şeklinde olduğu varsayılmıştır. $\mathrm{Bu}$ durumda problem, iki boyutlu skaler bir probleme dönüşür ve j'inci aydınlatma için herhangi bir noktadaki toplam elektrik alan vektörünü ifade eden $\boldsymbol{E}_{j}(\boldsymbol{r})=u_{j}(\boldsymbol{r}) \boldsymbol{e}_{\boldsymbol{z}}$ yerine $u_{j}(\boldsymbol{r})$ alan fonksiyonu ele alınabilir. $\mathrm{Bu}$ alanı $u_{j}(\boldsymbol{r})=u_{j}^{B}(\boldsymbol{r})+u_{j}^{S}(\boldsymbol{r}) \quad$ şeklinde iki alanının toplamı olarak düşünebiliriz. Burada $u_{j}^{B}(\boldsymbol{r})$ arka plan alanını yani gömülü cismin bulunmadığ 1 durumdaki toplam alanı, $u_{j}^{S}(\boldsymbol{r})$ ise gömülü cisimden saçılan alanı ifade etmektedir. Gömülü cisimden saçılma problemini tanımlayan iki integral denklem "cisim" ve "veri" denklemi olarak adlandırılır ve şu şekilde yazılır:

$$
\begin{aligned}
& u_{j}(\boldsymbol{r})= \iint_{D} G_{B}\left(\boldsymbol{r} ; \boldsymbol{r}^{\prime}\right) k_{B}{ }^{2}\left(\boldsymbol{r}^{\prime}\right) \chi\left(\boldsymbol{r}^{\prime}\right) u_{j}\left(\boldsymbol{r}^{\prime}\right) d \boldsymbol{r}^{\prime} \\
&+u_{j}^{B}(\boldsymbol{r}), \quad \boldsymbol{r} \in \mathrm{D}, \\
& u_{j}^{S}(\boldsymbol{r})= \iint_{D} G_{B}\left(\boldsymbol{r} ; \boldsymbol{r}^{\prime}\right) k_{B}^{2}\left(\boldsymbol{r}^{\prime}\right) \chi\left(\boldsymbol{r}^{\prime}\right) u_{j}\left(\boldsymbol{r}^{\prime}\right) d \boldsymbol{r}^{\prime} \\
& \boldsymbol{r} \in \mathrm{S}
\end{aligned}
$$

Burada $G_{B}$, şekli ve elektriksel özellikleri bilinen büyük cisim ile boş uzayın birleşiminden oluşan arka plana ilişkin Green fonksiyonunu, $\quad \chi$ ise gömülü cismin arka plandan farkını ifade eden kontrast fonksiyonunu temsil etmektedir. Kontrast fonksiyonun açık ifadesi $\chi(\boldsymbol{r})=k^{2}(\boldsymbol{r}) / k_{B}^{2}(\boldsymbol{r})-$ 1 şeklindedir. Gömülü cismin mevcut olmadiğ 1 ve olduğu durumlar için dalga sayılarının karelerini temsil eden $k_{B}^{2}$ ve $k^{2}$ herhangi bir noktada

$k_{B}^{2}(\boldsymbol{r})= \begin{cases}\omega^{2} \varepsilon_{1} \mu_{0}+i \omega \sigma_{1} \mu_{0}, & \boldsymbol{r} \in \mathrm{D} \\ \omega^{2} \varepsilon_{0} \mu_{0}+i \omega \sigma_{0} \mu_{0}, & \boldsymbol{r} \notin \mathrm{D}\end{cases}$

ve

$k^{2}(\boldsymbol{r})= \begin{cases}\omega^{2} \varepsilon_{G}(\boldsymbol{r}) \mu_{0}+i \omega \sigma_{G}(\boldsymbol{r}) \mu_{0}, & \boldsymbol{r} \in \mathrm{G} \\ k_{B}^{2}(\boldsymbol{r}), & \boldsymbol{r} \notin \mathrm{G}\end{cases}$

eşitlikleri ile tanımlanır. Denklem (1)'de ihtiyaç duyulan arka plan alanı $u_{j}^{B}$, [10]'da verilen düz saçılma yaklaşımı ile görece basit ve hızlı bir şekilde elde edilebilir. $\mathrm{Bu}$ yaklaşım doğrultusunda, gömülü cismin olmadiğ 1 durumdaki toplam alanın ve $\rho$ 'ya göre türevinin $\Gamma$ üzerinde sağlayacağı süreklilik ilişkileri

$u_{j}^{B(0)}=u_{j}^{B(1)}$

ve

$\frac{\partial u_{j}^{B(0)}}{\partial \rho}=\frac{\partial u_{j}^{B(1)}}{\partial \rho}$

şeklinde yazılır. Esas itibariyle alanların yüzey normali yönündeki türevleri sürekli olmakla birlikte, mevcut problem için, daha basit ifadeler olan $\rho$ 'ya göre türevlerin de sürekli olduğu [10]'da gösterilmiştir. Burada $u_{j}^{B(0)}$, D bölgesinin dışında kalan bölgedeki alanı, $u_{j}^{B(1)}$ ise $\mathrm{D}$ bölgesindeki alanı temsil etmektedir. $\mathrm{Bu}$ 
alanlar, $N$ yeterince büyük seçilmek şartıyla, $m=0$ ve $m=1$ için ayrı ayrı,

$$
\begin{aligned}
u_{j}^{B(m)}(\boldsymbol{r}) \cong \sum_{n=-N}^{N}( & a_{n}^{(m)} J_{n}\left(k_{m} \rho\right) \\
& \left.+b_{n}^{(m)} H_{n}^{(1)}\left(k_{m} \rho\right)\right) e^{i n \phi}
\end{aligned}
$$

şeklinde silindirik fonksiyonların serisi olarak yazilabilir. Burada $J_{n}$ ve $H_{n}^{(1)}, n$ 'inci mertebeden Bessel ve birinci tür Hankel fonksiyonlarını ifade etmektedir. Buna göre, $u_{j}^{B}$ 'nin herhangi bir noktadaki değerinin hesaplanabilmesi için $a_{n}^{(0)}$, $b_{n}^{(0)}$ ve $a_{n}^{(1)}, b_{n}^{(1)}$ katsayılarının belirlenmesi gerekir. $\mathrm{Bu}$ amaçla, $\Gamma$ üzerindeki süreklilik ilişkilerinde kullanılmak üzere, elektrik alanının $\rho$ 'ya göre türevi de, $m=0$ ve $m=1$ için ayrı ayr1,

$$
\begin{aligned}
\frac{\partial u_{j}^{B(m)}(\boldsymbol{r})}{\partial \rho} \cong \sum_{n=-N}^{N} & \left(a_{n}^{(m)} \frac{\partial J_{n}\left(k_{m} \rho\right)}{\partial \rho}\right. \\
& \left.+b_{n}^{(m)} \frac{\partial H_{n}^{(1)}\left(k_{m} \rho\right)}{\partial \rho}\right) e^{i n \phi}
\end{aligned}
$$

şeklinde birer seri ile ifade edilir. Buradaki silindirik fonksiyonların $\left(J_{n}\right.$ ve $H_{n}^{(1)}$ 'in) $\rho$ 'ya göre türevleri, analitik yöntemlerle hesaplanabilir türevlerdir ve açık ifadeleri [12]'de mevcuttur. Bilinmeyen katsayıların elde edilmesi için önerilen yaklaşım daha önce [10]'da kapsamlı olarak verildiğinden, yöntemin ayrıntıları bu çalışmada tekrarlanmayacaktır. Özetle, denklem (7) ve (8), denklem (5) ve (6)'daki süreklilik koşullarında yerine yazılır. Bütün silindirik fonksiyonlar ve normal türevleri birer Fourier serisi olarak ifade edilir. Ardından, her iki denklem de [10]'da tanımlandığı şekilde $e^{-i p \phi}, p=-N, \ldots, N$ kompleks üstel fonksiyonlarıyla çarpılarak ve ortogonallik özelliği kullanılarak, $a_{n}^{(0)}, b_{n}^{(0)}$ ve $a_{n}^{(1)}, b_{n}^{(1)}$ katsayıları için kolaylıkla çözülebilir boyutlarda bir lineer sistem elde edilir. Arka plan Green fonksiyonu $G_{B}\left(\boldsymbol{r} ; \boldsymbol{r}^{\prime}\right)$, gömülü cisim mevcut değilken $\boldsymbol{r}^{\prime}$ noktasındaki çizgisel kaynağın $\boldsymbol{r}$ noktasında oluşturacağı toplam alanı ifade ettiği için, aynı yaklaşımın [13]'de verildiği şekilde uyarlanmasıyla hesaplanabilir.
Arka plan alanı ve Green fonksiyonun hesaplanmasının ardından, Kontrast Kaynak (CSI) [7, 8] yöntemi kullanılarak kontrast $\chi(r)$ elde edilebilir. Denklem (1) and (2), operatörler aracılığıla $u_{j}=u_{j}^{B}+G^{D} w_{j} \quad$ ve $u_{j}^{S}=G^{S} w_{j}$ şeklinde daha sade ifadelerle gösterilebilir. Burada $G^{D}$ ve $G^{S}$ denklem (1) ve (2)'deki integral operatörleri, $w_{j}$ ise $j$ 'inci aydınlatma için $w_{j}=$ $\chi u_{j}$ şeklinde tanımlanan "kontrast kaynağı" temsil etmektedir. Bu denklemlerden $\chi$ 'nin elde edilmesi problemi kötü kurulmuş [9] ve doğrusal olmayan bir problemdir. CSI yöntemi bu problemi, cisim ve veri denklemlerine ilişkin hataların toplamlarının iteratif olarak minimize edilmesi olarak ele alır. Buna göre,

$F_{S}=\frac{\sum_{j}\left\|u_{j}^{S}-G^{S} w_{j}\right\|_{S}^{2}}{\sum_{j}\left\|u_{j}^{S}\right\|_{S}^{2}}, \quad F_{D}=\frac{\sum_{j}\left\|\chi u_{j}-w_{j}\right\|_{D}^{2}}{\sum_{j}\left\|\chi u_{j}^{B}\right\|_{D}^{2}}$

olmak üzere, $F=F_{S}+F_{D}$ şeklinde bir hata fonksiyonu tanımlanır. Denklem (9)'daki $\|.\|_{S}^{2}$ ve $\|.\|_{D}^{2}$, sirasiyla $S$ ve $D$ bölgelerindeki $\ell_{2^{-}}$ normu ifade etmektedir. Hata fonksiyonu $F$ 'yi minimize etmek için kontrast kaynakları $w_{j}$ ve kontrast $\chi$ sirayla güncellenir. Iterasyonların j'inci adımında $w_{j}$, hata fonksiyonu $F$ 'nin tamamını minimize etmek üzere

$w_{j}^{(n)}=w_{j}^{(n-1)}+\alpha_{j}^{w(n)} v_{j}^{w(n)}$

şeklinde güncellenir. Burada $v_{j}^{w}$, konjuge gradyan güncelleme yönünü ve $\alpha_{j}^{w}$ bu yöndeki adım boyutunu ifade etmektedir. Kontrast kaynağın güncellenmesinin ardından kontrast da $F_{D}$ 'yi minimize etmek üzere

$\chi^{(n)}=\chi^{(n-1)}+\alpha^{\chi^{(n)}} v^{\chi^{(n)}}$

şeklinde güncellenir. Kontrastın güncellenmesinde konjuge gradyan güncelleme yönü $v_{j}^{\chi}$ belirlenirken, $F_{D}$ 'nin $\chi$ 'ye göre gradyan kullanılır. Denklem (10) ve (11)'deki güncelleme yönlerinin $\left(v_{j}^{w}\right.$ ve $\left.v_{j}^{\chi}\right)$ ve bu yönlerdeki adım boyutlarının $\left(\alpha_{j}^{w}\right.$ ve $\left.\alpha_{j}^{\chi}\right)$ açık ifadeleri, başlangıç tahminleri $w_{j}{ }^{(0)}$ ve $\chi^{(0)}$ ile birlikte [8]'de verilmiştir. Hata fonksiyonu $F$ belirli bir değere yakınsayana veya önceden belirlenen bir iterasyon sayısına ulaşılana kadar $w_{j} \quad$ ve $\chi$ 'nin güncellenmesi sürdürülür. İterasyonların sonucunda ulaşılan kontrast $\chi(\boldsymbol{r})$ 
aracılığıyla, gömülü cismin elektriksel özelliklerinin dağılımı, yani $\varepsilon_{G}(\boldsymbol{r})$ ve $\sigma_{G}(\boldsymbol{r})$, belirlenir.

Gömülü saçıcının, elektriksel özellikleri bilinen homojen bir cisim olduğu, fakat cismin konumunun ve şeklinin bilinmediği özel durum için, daha once [11]'de modifiye edilmiş gradyan yönteminde kullanılmak üzere önerilmiş olan yaklaşım CSI'da kullanılabilir. Buna gore, kontrast fonksiyonunun reel ve imajiner k1sımlarını

$\chi_{t}(\boldsymbol{r})=\chi_{o b j, t} \Psi\left(\frac{\xi(\boldsymbol{r})}{\theta}\right) \quad t=1,2$

şeklinde yazabiliriz. Burada $t=1$ kontrastın reel kısmını, $t=2$ ise kontrastın imajiner kısmını belirtmek için kullanılmıştır. $\chi_{o b j, 1}$ ve $\chi_{o b j, 2}$, gömülü cismin bulunduğu noktalarda kontrastın reel ve imajiner kısımlarının alacağ 1 değerleri göstermekte olup, bilinen $\varepsilon_{G}$ ve $\sigma_{G}$ kullanılarak hesaplanırlar. Cismin bilinmeyen uzaysal dağılımı ise $\xi(\boldsymbol{r})$ ile belirlenmektedir. Gerçel değerli $\Psi$ fonksiyonu $\Psi(x)=$ $1 /\left(1+e^{-x}\right)$ şeklinde tanımlanmış olup, reel argüman $x$ 'in $-\infty$ ve $\infty$ arasındaki değerleri için 0 ve 1 arasında değerler almaktadır. Bir reel parametre olan $\theta$ 'nın seçimi için teorik bir yöntem önerilmemiştir ve uygun değer ampirik olarak tespit edilebilir. $\mathrm{Bu}$ durumda, $w_{j}$ 'nin (10)'da belirtildiği şekilde güncellenmesinin ardından, $\chi$ 'nin (11)'deki gibi güncellenmesinin yerine, cismin konumunun ve şeklinin belirlenmesi amaciyla $\xi$ 'nin

$\xi^{(n)}=\xi^{(n-1)}+\alpha^{\xi^{(n)}} v^{\xi^{(n)}}$

şeklinde güncellenmesi yeterli olacaktır. Güncelleme yönünü,

$$
\begin{array}{r}
g_{t}^{\xi^{(n)}}=\frac{\chi_{o b j, t}}{\theta} \exp \left(\frac{\xi^{(n-1)}}{\theta}\right)\left[\Psi\left(\frac{\xi(\boldsymbol{r})}{\theta}\right)\right]^{2} g_{t}^{\chi^{(n)}} \\
t=1,2
\end{array}
$$

olmak üzere, $v^{\xi^{(n)}}=\frac{g_{1}^{\xi^{(n)}}+g_{2}^{\xi^{(n)}}}{2}$

şeklinde seçebiliriz. Denklem (14)'de yer alan $g_{t}^{\chi^{(n)}}, \quad t=1,2, \quad F_{D}$ 'nin $\chi_{1}$ ve $\chi_{2}$ 'ye göre gradyanlarının $(n-1)$ 'inci iterasyon adımında hesaplanan değerlerini göstermektedir. Denklem (13)'teki adım boyutu $\alpha^{\xi^{(n)}}$ bir çizgi arama yöntemi [14] ile belirlenebilir.

\section{Sayısal Uygulamalar}

Önerilen yaklaşımı test etmek amacıyla, 2.7 $\mathrm{GHz}$ Intel Core i7 işlemciye ve $12 \mathrm{~GB}$ ana belleğe sahip bir PC kullanılarak, farklı simülasyonlar gerçekleştirilmiştir. Aşağıdaki örneklerde, içerisinde gömülü cisimler bulunan silindirik yapı, $7 \mathrm{~cm}$ yarıçaplı bir çember üzerinde eşit aralıklarla yerleştirilmiş 20 adet çizgisel kaynak ile $500 \mathrm{MHz}$ frekansında ayrı ayrı aydınlatılmıştır. Her aydınlatma için toplam alan $u_{j}, 6 \mathrm{~cm}$ yarıçaplı bir çember üzerinde eşit aralıklarla yerleştirilmiş 100 adet noktada Momentler Metodu (MoM) kullanılarak, aynı noktalardaki arka plan alanı $u_{j}^{B}$ ise denklem (7) ve (8)'deki seri gösterimi için $N=20$ seçilerek bu çalışmada önerilen yaklaşımla üretilmiştir. $\mathrm{Bu}$ iki alanın farkı alınarak $u_{j}^{S}$ hesaplanmış ve $0.1\left|u_{j}^{S}\right| e^{i \pi \gamma}$ şeklinde bir gürültü terimi eklenerek inversiyon verisi elde edilmiştir. Burada $\gamma, 0$ ve 1 arasında uniform dağılıma sahip bir rastgele değişkendir. CSI yöntemi ile inversiyon gerçekleştirilirken, $w_{j}$ için başlangıç tahmini, $w_{j}{ }^{(0)}$, [7]'de "geri yayılım" ile elde edilen ifade kullanılarak hesaplanmıştır ve iterasyonlar, hata fonksiyonu $F$ 'nin ardiş1k iki iterasyonda hesaplanan değerlei arasındaki fark $10^{-7}$ den küçük olduğunda veya maksimum iterasyon sayısı olan 1000'e ulaşıldığında sonlandırılmıştır. Birinci örnekte, Şekil 2(a)(b)'de gösterildiği gibi, dielektrik geçirgenliği ve elektrik iletkenliği sırası ile $\varepsilon_{1}=15 \varepsilon_{0}$ ve $\sigma_{1}=0,003(\mathrm{~S} / \mathrm{m})$ olan keyfi şekilli silindirik yapının içine $\varepsilon_{G, 1}=20 \varepsilon_{0}$ ve $\sigma_{G, 1}=0,09(\mathrm{~S} / \mathrm{m})$ parametrelerine sahip dikdörtgen bir cisim ve $\varepsilon_{G, 1}=18 \varepsilon_{0}$ ve $\sigma_{G, 1}=0,06(\mathrm{~S} / \mathrm{m})$ parametrelerine sahip üçgen bir cisim yerleştirilmiştir. 


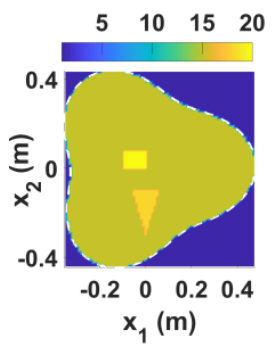

(a)

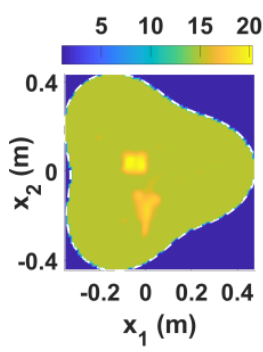

(e)

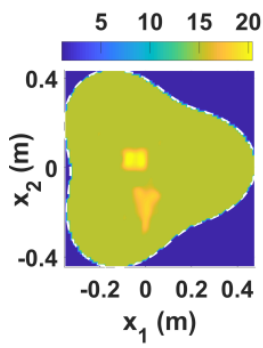

(i)

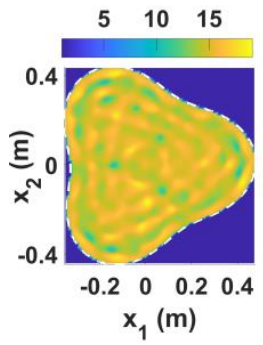

(m)

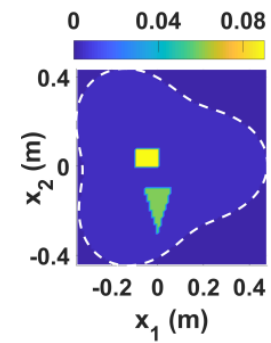

(b)

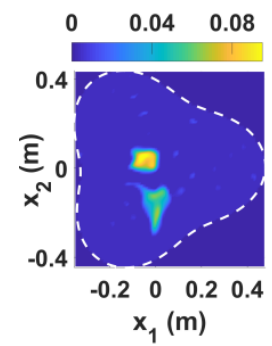

(f)

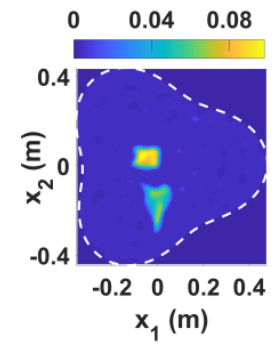

(j)

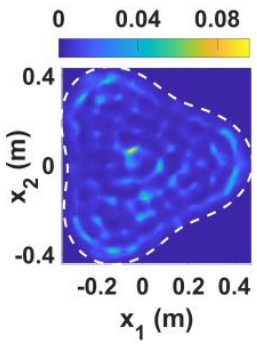

(n)

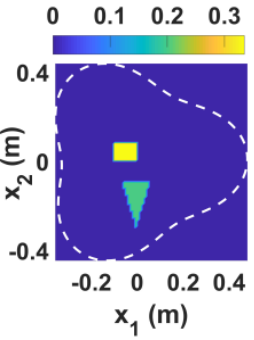

(c)

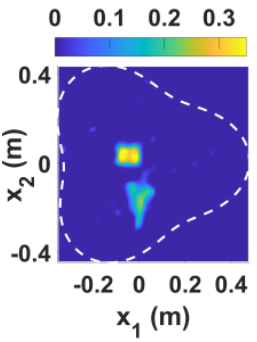

(g)

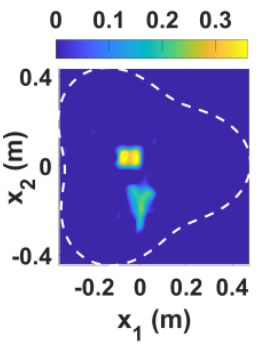

(k)

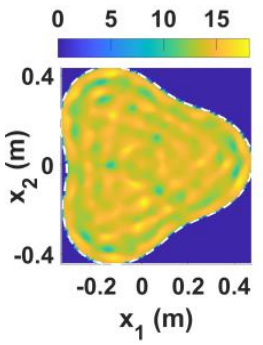

(o)

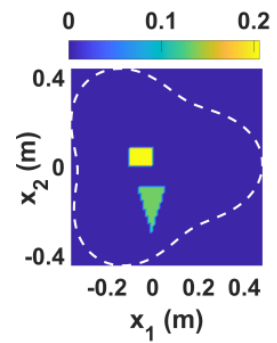

(d)

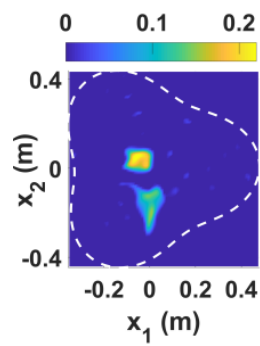

(h)

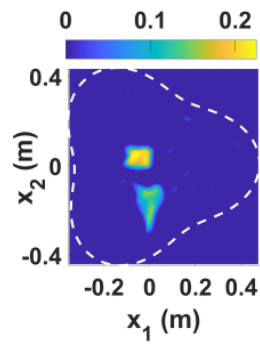

(1)

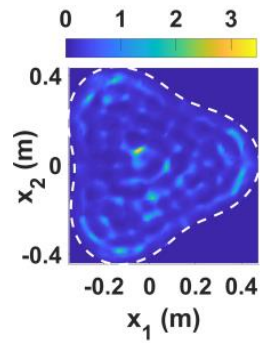

(p)

Şekil 2. Gömülü cisimlerin ve özellikleri bilinen silindirik yapının (a)bă̆ıl dielektrik geçirgenlik ve (b)iletkenlik dağllımları; silindirik yapının arka plan olarak kabul edilmesi durumunda hesaplanan kontrastın (c) reel ve (d) imajiner kisımlart. (e)-(h)Önerilen yöntem ile elde edilen sonuçlar. (i)-(l)Silindirik yapının arka plan olarak kabul edildiği ancak bu arka plana ilişkin alanın ve Green fonksiyonunun MoM ile hesaplandiğı durumda elde edilen sonuçlar.(m)-(p) Boş uzayın arka plan olarak kabul edildiği ve silindirik yapının bilinen özelliklerinin başlangıç tahmini olarak kullanıldiğı durumda elde edilen sonuçlar.

$\mathrm{Bu}$ çalışmada önerilen yaklaşım, gömülü cisimlerin bulunmadiğ 1 , onların yerinde elektriksel özellikleri $\varepsilon_{1}$ ve $\sigma_{1}$ olan malzemenin bulunduğu durumdaki dağılımın arka plan olarak tanımlanmasına dayanmaktadır. $\mathrm{Bu}$ nedenle, gömülü cisimlerin böylesi bir arka plana göre kontrastlarının reel ve imajiner kısımları hesaplanarak Şekil 2(c)-(d)'de gösterilmiştir. Bütün şekillerde, gömülü cismin içinde bulunduğu silindirik yapının sınırını göstermek için beyaz kesikli çizgiler kullanılmıştır. Önerilen yaklaşım kullanılarak oldukça başarılı sonuçlara ulaşılmış olup, CSI ile elde edilen kontrastın reel ve imajiner 
kısımları Şekil 2(g)-(h)'de ve bu kontrast değerlerine karşılık gelen dielektrik geçirgenlik ve iletkenlik dağılımları ise Şekil 2(e)-(f)'de verilmiştir. Gömülü cismin içinde yer aldığ silindirik yapının arka plan olarak tanımlanması yaklaşımı korunarak, arka plan alanı $u_{j}^{B}$ ve Green fonksiyonu $G_{B}$ 'nin geleneksel sayısal yöntemler, örneğin MoM, ile elde edilmesi de mümkündür. Böylesi bir yaklaşım, MoM kullanılarak, bu örnek için test edilmiştir. Şekil 2(g)-(j)'de görüldüğü gibi Şekil 2(c)-(f)'dekilere çok benzeyen sonuçlar elde edilmiştir. Ancak, bu sonuçlar elde edilirken kullanılan $u_{j}^{B}$ ve $G_{B}$ 'nin hesaplanması için ihtiyaç duyulan süre, önerilen yaklaşım ile 16 sn iken, MoM ile 71 sn'ye çıkmıştır. Gömülü cismin içinde bulunduğu silindirik yapının arka plan olarak tanımlanması yerine, boş uzayın arka plan olarak kabul edildiği ve bu yapının bilinen elektriksel özelliklerinin CSI'da başlangıç tahmini olarak kullanıldığ 1 bir yaklaşım da önerilebilir. Ancak bu yaklaşımın, bazı problemlerde tatmin edici sonuçlar verebilse de, bu örnekte gerçek durumdan çok uzak sonuçlar verdiği Şekil 2(m)-(p)'de görülmektedir.

Gömülü saçıcının, elektriksel özellikleri bilinen homojen bir cisim olduğu özel durum için önerilen ikili görüntüleme yaklaşımının sınanması amacıyla, birinci örnekteki gömülü cisimlerin her ikisinin de elektriksel özellikleri bir miktar arttırılarak Şekil 3(a)-(b)'de gösterildiği gibi $\varepsilon_{G, 1}=\varepsilon_{G, 2}=22 \varepsilon_{0}$ ve $\sigma_{G, 1}=$ $\sigma_{G, 2}=0,1(\mathrm{~S} / \mathrm{m})$ yapılmıştır.

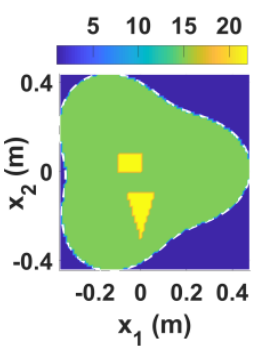

(a)

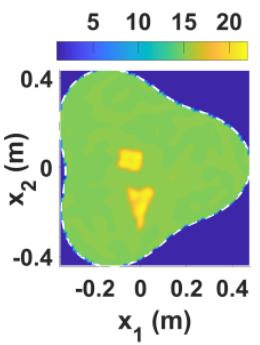

(e)

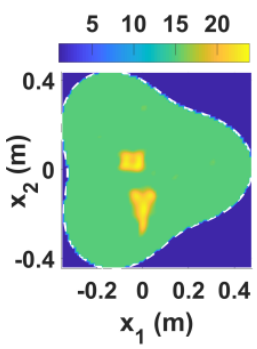

(i)

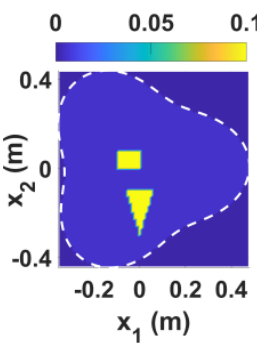

(b)

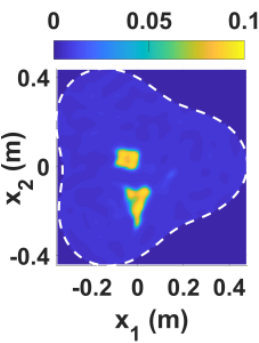

(f)

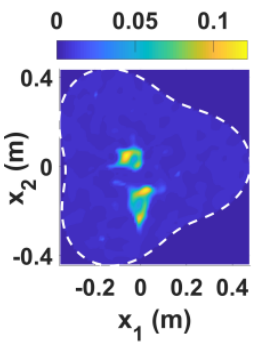

(j)

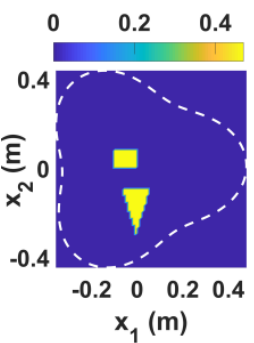

(c)

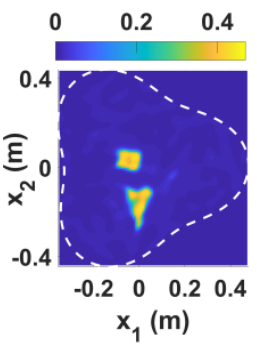

(g)

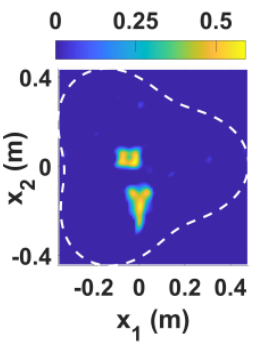

(k)

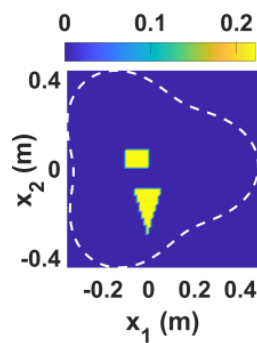

(d)

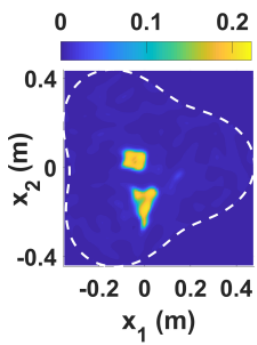

(h)

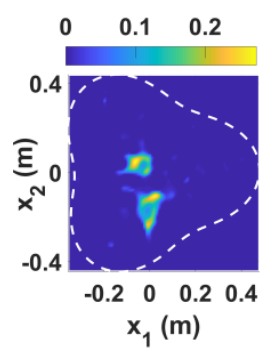

(1)

Şekil 3. Gömülü saçıcıların, elektriksel özellikleri bilinen homojen malzemeden oluştuğu özel durum için (a)bağıl dielektrik geçirgenlik ve (b)iletkenlik. (c)-(d) Silindirik yapının arka plan olarak kabul edilmesi durumunda hesaplanan kontrast. Önerilen yöntemin ikili görüntüleme yaklaşımı (e)-(h) kullanılarak ve (i)-(l) kullanılmadan uygulanması durumunda ile elde edilen sonuçlar. 
$\mathrm{Bu}$ durum için, CSI'nın önerilen ikili görüntüleme yaklaşımı kullanılarak uygulanmasıyla elde edilen kontrastın reel ve imajiner kısımları Şekil 3(g)-(h)'de verilmektedir. Bu kontrast değerlerine karşılık gelen bağıl dielektrik sabiti ve iletkenlik dağılımı ise Şekil3(e)-(f)'de görüldüğ̈̈ gibidir. $\mathrm{Bu}$ sonuçlar, standart CSI'nın uygulanması ile elde edilen ve Şekil 3(i)-(l)'de verilen sonuçlar ile karşılış̧ırıldığında, kontrastın reel kısmının iki durumda elde edilen değerlerinin birbirine yakın olduğu görülmektedir. Öte yandan, imajiner kısımda, ikili görüntüleme yaklaşımı ile elde edilen sonuçlar, standart CSI ile elde edilenlere kıyasla gerçek geometriye daha yakındır ve cismin geometrik özellikleri reel kısımla uyumlu bir şekilde belirlenebilmektedir. Ancak burada belirtmemiz gerekir ki, söz konusu yaklaşımın uygulanması, (12)'deki $\theta$ ve (13)'teki adım boyutunu tespit için gerçekleştirilecek çizgi arama işleminin ilk tahmini ve sonlandırma koşulları gibi birden fazla parametrenin ampirik olarak seçimini gerektirir.

\section{Sonuçlar}

Elektriksel ve geometrik özellikleri bilinen bir silindirik yapının içerisindeki cismin elektromagnetik dalgalar aracıllğıyla görüntülenmesi probleminin çözümünde, özellikleri bilinen yapının arka plan olarak kabul edilmesinin ve problemin formülasyonunun buna göre oluşturulmasının CSI ve benzeri nonlineer inversiyon yöntemlerinin performansını önemli oranda iyileştirdiği bilinmektedir. Bu çalışma esas olarak, böyle bir yaklaşıma dayanmaktadır. Ancak, arka plan alan $u^{B}$ ve Green fonksiyonu $G_{B}$ 'nin, daha önce düz saçılma problemleri için önermiş olduğumuz hızlı ve basit çözüm yöntemi ile hesaplanması sayesinde, bu durumda ihtiyaç duyulacak olan ilave hesaplama süresi belirgin şekilde azaltılmaktadır. Öte yandan, $u^{B}$ ve $G_{B}$ 'nin hesaplanması sırasında kullanılan düz saçılma yaklaşımına ilişkin, daha önce [10]'da belirtilmiş olan, sık ve hızlı değişimlerin olduğu karmaşık yüzeyli silindirik yapılar için sonuçların doğruluğunun azalması gibi güçlüklerin mevcut problemi de etkileyeceği açıktır. Son olarak, gömülü saçıcının, elektriksel özellikleri bilinen homojen bir cisim olduğu özel durumda, daha önce modifiye edilmiş gradyan yönteminde kullanılmak üzere önerilmiş olan ikili görüntüleme yaklaşımının CSI'ya uyarlanması ile makul sonuçlar elde edilebileceği gösterilmiştir. Ancak, bu ikili görüntüleme yaklaşımının uygulanması sirasinda birden fazla parametrenin uygun değerlerinin ampirik olarak belirlenmesi gerekliliği, yaklaşımın farklı problemlerde uygulanabilirliğini kısıtlamaktadır.

\section{Kaynaklar}

[1] Tiberi, G., Ghavami, N., Edwards, D. J., Monorchio, A., (2011). Ultrawideband microwave imaging of cylindrical objects with inclusions, IET Microwaves, Antennas \& Propagation, 5, 12, 14401446.

[2] Abubakar, A., Hu, W., van den Berg, P. M., Habashy, T. M., (2011). A finite-difference contrast source inversion method, Inverse Problems, 24, 6, 065004.

[3] Gilmore, C., Zakaria, A., Pistorius, S., LoVetri, J., (2013). Microwave Imaging of Human Forearms: Pilot Study and Image Enhancement, International Journal of Biomedical Imaging, 2013, 673027.

[4] Lu, C., Zhong, X. G., (2003). Image reconstruction of two-dimensional objects inside dielectric walls, Microwave and Optical Technology Letters, 36, 2, 91-95.

[5] Meng, Q., Ye, D., Huangfu, J., Li, C., Ran, L., (2016). Experimental investigation on through-wall imaging based on non-linear inversions, Electronics Letters, 52, 23, 1933-1935.

[6] Semenov, S. Y., Nulyshev, A. E., Abubakar, A., Posukh, V. G., Sizov, Y. E., Souvorov, A. E., van den Berg, P.M.,Williams, T. C., (2005). MicrowaveTomographic Imaging of the High DielectricContrast Objects Using Different ImageReconstruction Approaches, IEEE Transactions on Microwave Theory and Techniques, 53, 7, 22842294. 
[7] Van den Berg, P. M., Kleinman, R. E., (1997). A contrast source inversion method, Inverse Problems, 13, 6, 1607-1620.

[8] Van den Berg, P. M., van Broekhoven, A. L., Abubakar, A., (1999). Extended contrast source inversion, Inverse Problems, 15, 5, 1325-1344.

[9] Colton, D., Kress, R., (2013). Inverse Acoustic and Electromagnetic Scattering Theory, Springer, New York.

[10] Aslanyürek, B., Gürbüz, T. U., (2017). A continuitybased series solution for electromagnetic scattering by arbitrary shaped multilayer cylinders: TM case, IEEE Transactions on Antennas and Propagation, $\mathbf{6 5}, 2,812-819$.
[11] Souriau, L., Duchêne, B., Lesselier, D., Kleinman, R. E., (1996). Modified gradient approach to inverse scattering for binary objects in stratified media, Inverse Problems, 12, 4, 463-481.

[12] Polyanin, A.D., Manzhirov, A.V., (2007). Handbook of Mathematics for Engineers and Scientists, Chapman \& Hall/CRC., Boca Raton.

[13] Gürbüz, T. U., (2018). Computation of Two Dimensional Green's Function for Arbitrary Shaped Multilayer Cylinders. IEEE Antennas and Wireless Propagation Letters, 17, 12, 2241-2245.

[14] Antoniou, A., Lu, W.-S., (2007). Practical Optimization: Algorithms and Engineering Applications, Springer, New York. 